\title{
Geopolitical Risk and the Return Volatility of Islamic Stocks in Indonesia and Malaysia: A GARCH-MIDAS Approach
}

\author{
Umar B. Ndako' ${ }^{\text {, }}$, Afees A. Salisu', Muritala O. Ogunsiji ${ }^{3}$ \\ ${ }^{1}$ Central Bank of Nigeria, Abuja, Nigeria, ${ }^{2}$ Centre for Econometric \& Allied Research, University of Ibadan, Ibadan, Nigeria, ${ }^{3}$ Department of \\ Economics, Fountain University, Osogbo, Nigeria \\ Keywords: geopolitical risk, islamic stocks, predictability, out-of-sample forecast, garch-midas
}

https://doi.org/10.46557/001c.24843

\section{Asian Economics Letters}

Vol. 2, Issue 3, 2021

In this paper, the predictive value of geopolitical risk (GPR) for the return volatility of Islamic stocks in Indonesia and Malaysia is examined. GPR data, whether global or country-specific, heighten the return volatility of Islamic stocks in both countries, albeit with a greater impact on Indonesia. Additional analyses show improved out-of-sample forecast gains with the inclusion of GPR data in the predictive model of the return volatility of Islamic stocks.

\section{Introduction}

In this study, we contribute to the literature on the predictability of Islamic return volatility by examining the predictive content of geopolitical risk (GPR), focusing on Indonesia and Malaysia, the two most prominently referenced economies in Islamic finance that equally provide investment opportunities in conventional stocks. ${ }^{1}$ Generally, we test the hypothesis that an increase in GPR will lead to a decrease in the future return volatility of stocks, since higher risks discourage future investments in risky assets, thus lowering future trading and, by extension, volatility in these assets, ceteris paribus.

Our hypothesis is important to both investors and policymakers, since the effect of GPR on investment decisions and the resultant performance of underlying financial assets would be particularly severe in economies where geopolitical tensions are relatively stronger and more persistent (Bouri et al., 2019). The recent upsurge in the literature focusing on GPR and its impact on national and global macroeconomic variables motivated our interest in the nexus (e.g., Bouri et al., 2019; Godil et al., 2020; Smales, 2021; Yang et al., 2021; Zhou et al., 2020). ${ }^{2}$ However, we differ from these studies in the following ways. First, we adopt a generalized autoregressive conditional heteroskedasticity-mixed data sampling (GARCH-MIDAS) approach that accommodates mixed (high and low) data frequencies to avoid information loss associated with the use of strictly low-frequency data. Second, we extend our analyses to in- clude out-of-sample forecasts, since in-sample predictability is no guarantee for improved forecasts. Third, we consider both country-specific and global GPR indices, including GPR acts and GPR threats, thus providing a reasonable basis for evaluating the robustness of our empirical results.

Our results advance the literature on the predictive value of GPR by using an alternative approach to provide evidence of its out-of-sample predictive power for the return volatility of Islamic stocks in major stakeholder countries. We show that GPR, whether global or country- specific, has predictive content for the return volatility of Islamic stocks in both Indonesia and Malaysia, ${ }^{3}$ albeit with greater influence on the former than the latter. While GPR acts offer better forecast outcomes than GPR threats, out-of-sample predictability shows the performance of the GPR-based GARCH-MIDAS model is superior to the benchmark model with realized volatility across all forecast horizons.

The remainder of the paper is organized as follows. Section II discusses the data and methodology and the results and discussions. Section III presents the conclusion of the paper.

\section{Data and Results}

\section{A. Data}

Our datasets consist of daily Islamic stock data for both Indonesia and Malaysia from November 13, 2008, to August

\footnotetext{
a Corresponding author email: umarbida@gmail.com

1 For instance, Malaysia has the most integrated Islamic financial market in the world and enjoys a dual market system, which allows for trading in both Islamic and conventional stocks. Similarly, although a late entry, the Indonesian market is now the fastest growing Islamic finance market in the world.

2 Narayan \& Phan (2019) offer useful guidance in the Islamic finance literature and discuss the use of models to analyze the return predictability of Islamic stocks.

3 This outcome corroborates the findings of Salisu et al. (2020), who emphasize the role of global factors when modeling Islamic stocks.
} 
3, 2020, and monthly country-specific GPR data for both Indonesia and Malaysia from November 2008 to August 2020. Data on global GPR, as well as its variants, GPR acts and GPR threats, are also used for robustness. The Islamic stock data are downloaded from Bloomberg, and the GPR data are obtained from Matteo Iacoviello's website (https://www.matteoiacoviello.com/gpr.htm). The GPR series is defined as the risks associated with war, terrorism, and tension among states that affect the normal course of international relations (Caldara \& Iacoviello, 2018). The GPR index captures both acts and threats of risk that result in geopolitical instability, and it is constructed by counting the number of articles discussing geopolitical events and associated risks in 11 leading English language newspapers, but excluding events such as climate change, democratic political events (Brexit), and global economic events (e.g., the global financial crisis). ${ }^{4}$

\section{B. Results}

Given a daily stock return series computed as the logarithmic return $r_{i, t}=\ln \left(P_{i, t}\right)-\ln \left(P_{i-1, t}\right)$, where $P_{i, t}$ represents the price for day $i$ in month $t$, with $t=1, \ldots, T$ and $i=1, \ldots, N_{t}$ denoting monthly and daily frequencies, respectively, and $N_{t}$ the number of days in a given month $t$, we construct a GARCH-MIDAS-X model where the (natural logarithm of) GPR is as follows:

$$
\begin{aligned}
& r_{i, t}=\mu+\sqrt{\tau_{t} \times h_{i, t}} \times \varepsilon_{i, t}, \quad \varepsilon_{i, t} \mid \Phi_{i-1, t} \sim N(0,1), \\
& \forall i=1, \ldots, N_{t} \\
& h_{i, t}=(1-\alpha-\beta)+\alpha \frac{\left(r_{i-1, t}-\mu\right)^{2}}{\tau_{i}}+\beta h_{i-1, t} \\
& \tau_{i}^{(r w)}=m^{(r w)}+\theta^{(r w)} \sum_{k=1}^{K} \phi_{k}\left(w_{1}, w_{2}\right) X_{i-k}^{(r w)}
\end{aligned}
$$

where equation (1) defines the mean equation, while equations (2) and (3) describe the conditional variance components specified, respectively, for short- and long-run components. In terms of the parameter definitions, $\mu$ is the unconditional mean of the return series, as specified in equation (1); $h_{i t}$ is the short-run component of high-frequency data, which, as specified in equation (2), follows a $\operatorname{GARCH}(1,1)$ process, where $\alpha$ and $\beta$ are the ARCH and GARCH terms, respectively, conditioned to be positive and/ or at least zero $(\alpha>0$ and $\beta \geq 0)$ and summing to less than unity $(\alpha+\beta<1)$; and $\tau_{t}$ captures the long-run component that incorporates the exogenous macroeconomic series (or realized volatility when there is no macroeconomic series) and involves repeating the monthly value throughout the days in that month. The superscript $(r w)$ in equation (3) denotes the implementation of a rolling-window framework (which allows the secular long-run component to vary daily), while $m$ represents the long-run component inter- cept. The focus of our analysis is the MIDAS slope coefficient $(\theta)$, which indicates the predictability of the incorporated exogenous predictor $X_{i-k}$, where $\phi_{k}\left(w_{1}, w_{2}\right) \geq 0, k=1, \ldots, K$, is the weighting scheme that must sum to one for the parameters of the model to be identified; and $K$ is chosen based on the log-likelihood statistic for each predicted-predictor series pair, to filter the secular component of the MIDAS weights. ${ }^{5}$

In the final setup, we compare the out-of-sample forecast performance of the GPR-based GARCH-MIDAS (GARCHMIDAS-GPR) model with that of the benchmark model involving realized volatility (GARCH-MIDAS-RV). Consequently, we consider multiple forecast horizons $(h=5,10$, 20) and employ the modified Diebold-Mariano (1995) test, following the test of Harvey et al. (1997), which calculates the $p$-values and addresses the issue with the assumption of zero covariance at unobserved lags to formally ascertain significant differences in the forecast errors associated with the contending models.

Table 1 presents the predictability results for countryspecific GPR and global GPR, including the variants GPR threats and GPR acts, for the return volatility of Islamic stocks in Indonesia and Malaysia. Our discussion focuses on the ability of the GPR data to predict the future return volatility of the Islamic financial market. Thus, for brevity, only the parameters of interest are presented and discussed accordingly. $^{6}$

The results in Table 1 show that the impact of any shock to the Islamic stock markets of both Indonesia and Malaysia is temporary, regardless of whether the GPR is country-specific or global. Nonetheless, the shock effect may persist for a while, given that the sum of the ARCH $(\alpha)$ and GARCH $(\beta)$ terms is close to unity (see also Salisu et al., 2020). The slope coefficient $(\theta)$ that measures the impact of GPR on return volatility is negative for both countries, although it is not significant in the country-specific GPR case in Indonesia. This result implies that country-specific GPR accurately predicts return volatility only for Malaysia, and not Indonesia. We attribute this to the low coverage of incidences in Indonesia by foreign media or the deliberate suppression of news by the national government to prevent the flight of capital from the country.

Meanwhile, both countries record negative and significant slope coefficients for global GPR, implying that the incidence of the latter decreases the volume of trade in Islamic stocks for both countries. We find this result very probable, since most of the documented risk advantages Islamic stocks have over conventional stocks (e.g., avoidance of interest, speculation, gambling, excessive leverage, credit crunches, and complicated financial products) are finance based and do not account for GPR. ${ }^{7}$ Therefore, it is only reasonable that investor decisions regarding conven-

\footnotetext{
4 For details on the GPR index, see https://www.matteoiacoviello.com/gpr.htm.

5 See Engle et al. (2013) for technical details on GARCH-MIDAS regressions.

6 The complete results of the estimated GARCH-MIDAS model are available upon request from the corresponding author.

7 See Siddiqi (2009).
} 
Table 1. In-sample predictability results

\begin{tabular}{|c|c|c|c|}
\hline & $\alpha$ & $\beta$ & $\theta$ \\
\hline \multicolumn{4}{|c|}{ GPR (Country) } \\
\hline Malaysia & $\begin{array}{c}0.0902^{* * *} \\
(0.0073)\end{array}$ & $\begin{array}{c}0.8813^{* * *} \\
(0.0087)\end{array}$ & $\begin{array}{c}-1.1085^{* * *} \\
(0.2250)\end{array}$ \\
\hline \multirow[t]{2}{*}{ Indonesia } & $\begin{array}{l}0.0941^{* * *} \\
(0.0098)\end{array}$ & $\begin{array}{l}0.8732^{* * *} \\
(0.01329)\end{array}$ & $\begin{array}{c}-1.109 \\
(1.1598)\end{array}$ \\
\hline & & GPR & \\
\hline Malaysia & $\begin{array}{c}0.0894^{* * *} \\
(0.0069)\end{array}$ & $\begin{array}{c}0.8895^{* * *} \\
(0.0080)\end{array}$ & $\begin{array}{l}-0.2017^{*} \\
(0.1050)\end{array}$ \\
\hline \multirow[t]{2}{*}{ Indonesia } & $\begin{array}{c}0.0931^{* * *} \\
(0.0090)\end{array}$ & $\begin{array}{c}0.8727^{* * *} \\
(0.0120)\end{array}$ & $\begin{array}{c}-1.2267^{* * *} \\
(0.3588)\end{array}$ \\
\hline & & GPR Threat & \\
\hline Malaysia & $\begin{array}{c}0.0892^{* * *} \\
(0.0068)\end{array}$ & $\begin{array}{c}0.8898^{* * *} \\
(0.0080)\end{array}$ & $\begin{array}{c}-0.1588 \\
(0.0991)\end{array}$ \\
\hline \multirow[t]{2}{*}{ Indonesia } & $\begin{array}{c}0.0927^{* * *} \\
{[0.0089]}\end{array}$ & $\begin{array}{c}0.8735^{* * *} \\
{[0.0120]}\end{array}$ & $\begin{array}{c}-1.1828^{* * *} \\
{[0.3316]}\end{array}$ \\
\hline & & GPR Act & \\
\hline Malaysia & $\begin{array}{l}0.0929^{* * *} \\
{[0.0074]}\end{array}$ & $\begin{array}{l}0.8779^{* * *} \\
{[0.0090]}\end{array}$ & $\begin{array}{c}-0.6840^{* * *} \\
{[0.1502]}\end{array}$ \\
\hline Indonesia & $\begin{array}{l}0.0958^{* * *} \\
{[0.0087]}\end{array}$ & $\begin{array}{c}0.8709^{* * *} \\
{[0.0113]}\end{array}$ & $\begin{array}{l}-1.2704^{*} \\
{[0.6846]}\end{array}$ \\
\hline
\end{tabular}

Notes: This table reports the in-sample predictability results: $\mu$ - unconditional mean of stock price returns, $\alpha, \beta, \theta$ represents ARCH term, GARCH term, and slope coefficient, respectively. The figures in square brackets are the standard errors of the parameter estimates, while ${ }^{* * * * * * *}$ and $*$ indicate statistical significance at the $1 \%, 5 \%$ and $10 \%$ levels, respectively.

tional stocks in times of GPR do not significantly differ from those regarding Islamic stocks, especially in notably dual economies such as Indonesia and Malaysia. Besides, the integrated nature of these markets, especially the Malaysian market, ensures that the investors in Islamic stocks are not only from Muslim-dominated countries, but also from nonIslamic countries (Ling et al., 2020). However, the results reveal that the impact is more prominent in Indonesia than in Malaysia.

Going further to validate our results, we conduct similar analyses using different GPR proxies, namely, GPR threats and GPR acts. Predictability results for GPR threats are only significant for Indonesia, and not for Malaysia. Meanwhile, both countries record a negatively significant result for GPR acts. Therefore, one can conclude that GPR acts are also a major predictor of the return volatility of Islamic stocks in both Indonesia and Malaysia.

We also conduct out-of-sample forecast analysis by evaluating the relative forecast performance of the two competing GARCH-MIDAS models, that is, the GARCH-MIDAS model with GPR and the conventional variant with realized volatility (which excludes the GPR predictor). Based on the modified Diebold-Mariano (1995) test, we find that our proposed model that accounts for GPR data is consistently favored for all forecast horizons across the various proxies for GPR, except for the case of GPR acts, where the benchmark model outperforms the proposed model, but only for Indonesia (see Table 2). In sum, the inclusion of GPR in the predictive model of the return volatility of Islamic stocks improves forecast accuracy. Therefore, financial analysts and investors alike seeking to maximize returns in Islamic stock markets may need to take cognizance of the considered risk factor when making future investment decisions.

\section{Concluding Remarks}

In this paper, we focus on establishing the predictability of GPR for the return volatility of Islamic stocks in Indonesia and Malaysia, the two most referenced countries giving prominence to both Islamic and conventional stocks. We consider both country-specific GPR and global GPR, including GPR acts and threats. All the analyses are rendered for both in-sample and out-of-sample predictability. In all, we find that the return volatility of Islamic stocks in both Indonesia and Malaysia is vulnerable to GPR, albeit with greater influence in Indonesia than in Malaysia. While GPR acts offer better forecast outcomes than GPR threats, the out-of-sample predictability shows that the GPR-based GARCH-MIDAS model performs better than the benchmark model with realized volatility across all forecast horizons. However, economic significance tests to further establish these claims are set aside for future studies.

Submitted: May 19, 2021 AEST, Accepted: June 06, 2021 AEST 
Table 2. Out-of-Sample Forecast Evaluation

\begin{tabular}{|l|c|c|c|}
\hline & $h=5$ & $h=10$ & $h=20$ \\
\hline & & GPR (Country) & \\
\hline Malaysia & $-7.1768[0.0000]$ & $-5.4152[0.0000]$ & $-4.2822[0.000]$ \\
\hline Indonesia & $-4.5518[0.0000]$ & $-3.2288[0.0013]$ & $-2.3345[0.0196]$ \\
\hline & & GPR & $-5.9801[0.0000]$ \\
\hline Malaysia & $-11.1504[0.0000]$ & $-8.1577[0.0000]$ & $-4.4749[0.0000]$ \\
\hline Indonesia & $-6.8568[0.0000]$ & $-5.1937[0.0000]$ & $-3.0955[0.0020]$ \\
\hline & & GPRT & $-4.4193[0.0000]$ \\
\hline Malaysia & $-4.5910[0.0000]$ & $-3.6504[0.0002]$ & $-6.4600[0.0000]$ \\
\hline Indonesia & $-7.3248[0.0000]$ & GPRA & $-6.3705[0.0000]$ \\
\hline & & $-8.0322[0.0000]$ & $-1.3945[0.1633]$ \\
\hline Malaysia & $-10.5937[0.0000]$ & $-1.6893[0.0913]$ & \\
\hline Indonesia & $-2.1857[0.0289]$ & & \\
\hline
\end{tabular}

Notes: This table reports the modified Diebold and Mariano test as per Harvey et al. (1997). The p-values are reported in square brackets. If the statistic is negative and significant, the GARCH-MIDAS-GPR is preferred while the GARCH-MIDAS-RV is chosen if the test statistic is positive and significant. The forecast performance of the two competing models is assumed to be identical if the statistic is insignificant. 


\section{REFERENCES}

Bouri, E., Demirer, R., Gupta, R., \& Marfatia, H. A. (2019). Geopolitical risks and movements in Islamic bond and equity markets: A note. Defence and Peace Economics, 30(3), 367-379. https://doi.org/10.1080/10 $\underline{242694.2018 .1424613}$

Caldara, D., \& Iacoviello, M. (2018). Measuring geopolitical risk. FRB International Finance Discussion Paper, 1222, 1-66. https://doi.org/10.17016/ifdp.201 $\underline{8.1222}$

Diebold, F. X., \& Mariano, R. S. (1995). Comparing Predictive Accuracy. Journal of Business and Economic Statistics, 13, 253-263.

Engle, R. F., Ghysels, E., \& Sohn, B. (2013). Stock market volatility and macroeconomic fundamentals. Review of Economics and Statistics, 95(3), 776-797. htt ps://doi.org/10.1162/rest_a_00300

Godil, D. I., Sarwat, S., Sharif, A., \& Jermsittiparsert, K. (2020). How oil prices, gold prices, uncertainty and risk impact Islamic and conventional stocks? Empirical evidence from QARDL technique. Resources Policy, 66, 10163. https://doi.org/10.1016/i.resourpo $\underline{1.2020 .101638}$

Harvey, D., Leybourne, S., \& Newbold, P. (1997). Testing the equality of prediction mean squared errors. International Journal of Forecasting, 13(2), 281-291. ht tps://doi.org/10.1016/s0169-2070(96)00719-4

Ling, P.-S., Abdul-Rahim, R., \& Said, F. F. (2020). The effectiveness of technical strategies in Malaysian Shariah vs conventional stocks. ISRA International Journal of Islamic Finance, 12(2), 195-215. https://do i.org/10.1108/ijif-08-2018-0092
Narayan, P. K., \& Phan, D. H. B. (2019). A survey of Islamic banking and finance literature: Issues, challenges and future directions. Pacific-Basin Finance Journal, 53, 484-496. https://doi.org/10.1016/j.pacfi $\underline{\text { n.2017.06.006 }}$

Salisu, A. A., Ndako, U. B., Adediran, I. A., \& Swaray, R. (2020). A fractional cointegration VAR analysis of Islamic stocks: A global perspective. The North American Journal of Economics and Finance, 51, 101056. https://doi.org/10.1016/i.najef.2019.101056

Siddiqi, M. N. (2009). Current financial crisis and Islamic economics. Insights, 1(3), 141-150.

Smales, L. A. (2021). Geopolitical risk and volatility spillovers in oil and stock markets. The Quarterly Review of Economics and Finance, 80, 358-366. http s://doi.org/10.1016/j.qref.2021.03.008

Yang, K., Wei, Y., Li, S., \& He, J. (2021). Geopolitical risk and renewable energy stock markets: An insight from multiscale dynamic risk spillover. Journal of Cleaner Production, 279, 123429.

Zhou, M.-J., Huang, J.-B., \& Chen, J.-Y. (2020). The effects of geopolitical risks on the stock dynamics of China's rare metals: A TVP-VAR analysis. Resources Policy, 68, 101784. https://doi.org/10.1016/i.resourpo $\underline{1.2020 .101784}$ 